\title{
Proceeding
}

9th INSHS International Christmas Sport Scientific Conference, 4-6 December 2014. International Network of Sport and Health

Science. Szombathely, Hungary

\section{Critical moments in freestyle BMX/MTB and their impact on prestart conditions}

\author{
DAMJAN SIRIŠKI $\square$, VIKTOR PACHOLÍK, SYLVA HŘEBIČKOVÁ, JAN MACH \\ Faculty of Sport Science, Masaryk University, Brno, Czech Republic
}

\begin{abstract}
Siriški, D., Pacholík, V., Hřebíčková, S., \& Mach, J. (2015). Critical moments in freestyle BMX/MTB and their impact on prestart conditions. J. Hum. Sport Exerc., 9(Proc1), pp.S205-S211. The purpose of this study was to describe critical moments in freestyle competition, analyse mental state of elite freestyle cycling athletes before competition and to evaluate changes of their subjective psychological experiences. In our research we compared results of freestyle cyclists with results of reference group of elite track cyclists. We used semi-structured interviews and two standardized questionnares: SUPSO test and SPARO test. Statistically significant differences were found while comparing SPARO test and SUPSO test results of freestyle cyclists and the reference group. Some of the differences were related to components, that smartly expresses specificity of freestyle cyclists' mentality. Elite freestyle riders' general and precompetition mentality is specific, which is caused by specificity of this extreme cycling discipline. There are numerous factors that impact these athletes during the competition, more than in any other of cycling disciplines. Psychological preparation of freestyle cycling athletes would contribute to improve their performance. Key words: PSYCHOLOGICAL EXPERIENCES, FREESTYLE CYCLING, SUPSO, SPARO.
\end{abstract}

Corresponding author. Faculty of Sport Science, Masaryk University, Žerotínovo nám. 617/9,601 77, brno, czech republic E-mail: 156111@mail.muni.cz 9th INSHS International Christmas Sport Scientific Conference, 4-6 December 2014. International Network of Sport and Health Science. Szombathely, Hungary.

JOURNAL OF HUMAN SPORT \& EXERCISE ISSN 1988-5202

(c) Faculty of Education. University of Alicante

doi:10.14198/jhse.2015.10.Proc1.07 


\section{INTRODUCTION}

Freestyle cycling disciplines are the youngest branch of cycling and although they are not far as popular as traditional cycling disciplines, they have been growing fast and are getting a lot of attention.

After two decades of existence of these disciplines, scientific publications, which study impact of training on body composition of riders or describe training methods, started to come into existence.

Scientific interest also explores psychological aspects of this sport. One of the frequent theoretically and practically explored spheres in sport psychology is the subject of personality in sport. Insufficient knowledge of freestyle cycling athlete's personality and insufficient self-reflection represent radical limiting factors for systematic work and cyclist's growth of performance.

The aim of our thesis was to describe critical moments in freestyle cycling race from the perspective of competitor and compare them with the personality traits of competitors.

Mikšik (2004) describes personality state as a dynamic quantity, for which is typical variability of activation of psyche with changes of basic qualities of experiencing. It reflects in subject's dynamics of inner (psychic) and external (motoric) activity.

\section{METHODS}

7 elite athletes attended our research as the test group. We used semi-structured interviews to get information about critical moments during competition period. Questionnaires SUPSO (Subjective experiences and personality states; Mikšík, 2004) and SPARO were other diagnostic tools in our research. We used results of our colleague's research that studied mental states and personal characteristics of elite track cyclists as results of a reference group.

In semi-structured interviews the main objective was to

Questionnaire SUPSO is used to describe and evaluate the dynamics of subjective experiences and personality states (Mikšík, 2004). Mental state can be described in its overall, integrated structure using the proportional representation of each component.

The measured components of mental state are:

$P=$ psychological well-being (feeling of satisfaction, a pleasant mood and pleasant mental warm-up, which is often accompanied by feelings of euphoria and confidence). This component shows a degree of freshness, satisfaction, peace and mental balance, optimism and good mood.

$A=$ activity, vigorousness (feelings of power and energy which are associated with a hankering after the action). It is a readiness for active interaction among various situational variables. It can be described with the qualities of psychological phenomena, such as vigorousness and assertiveness.

$0=$ impulsiveness, letting off steam (uncontrolled, spontaneous release of energy stress and mental tension). Described by feelings like moodiness, difficulty in self-control, explosiveness and irritability. 
$N=$ mental restlessness, discomfort (experiencing psychological stress, when it is not possible to find ways to release it). Characteristic symptoms are mental and motoric restlessness, annoyance, discontent, impatience and restlessness.

$D=$ mental depression, tiredness (complex of feelings and states, of which the main characteristics represent a tendency towards passivity and apathy).

$U=$ anxious expectations and fears (feelings of insecurity, fear of the possible future consequences, etc.

$S=$ sadness (these experiences can be expressed by adjectives sad, lonely, hypersensitive, unhappy). It can be defined as a passive experiencing of situational variables. Experiences are not turned out to interact with the outer environment, but "inside".

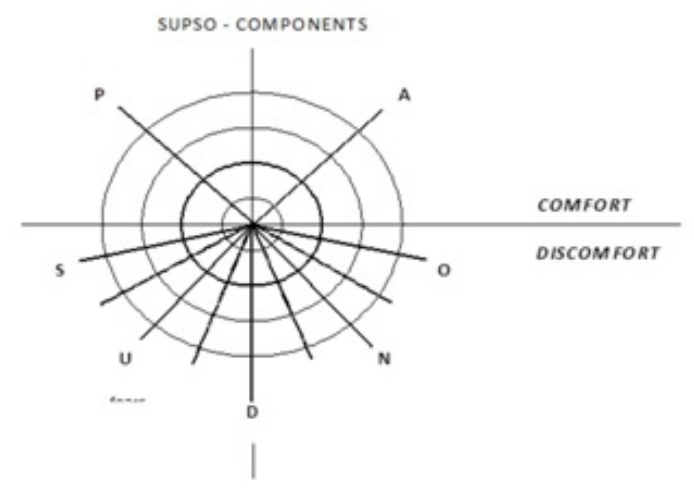

Figure 1. Target graph showing subcomponents of mental state measured by a standardized questionnaire SUPSO.

The results obtained via the test SUPSO can be graphically represented and interpreted using the target graph (Fig. 1). Circle, which is marked in bold line connects average values of mental state in population. The horizontal axis divides the target graph into upper and lower half and the vertical axis divides it into the left and right half. The intersection of the horizontal and vertical axes forms the centre of all the circles in the graph. The vertical axis divides the components of experiencing (upper left quadrant) and activation (upper right quadrant). The scale of depression and exhaustion occupies the interfacing (right-left) neutral position. The horizontal axis separates the components of experiencing psychological well-being, of which are typical: positive mood and excitement to the activity (upper left and right quadrant) and components of psychological discomfort, of which are typical: unpleasant or demobilizing mood and arousal (lower left and right quadrant).

SPARO questionnaire represents basic tools of diagnostic battery DIAROS. It is an advanced option for diagnosis of structure and dynamics of basal auto-regulation and integration of inner and external personal activities and mental resistance.

Basic components of basal mental integration: 
$K O=$ cognitive variability relates to cognitive functions. High values of variability is characteristic for tendencies to change, high quantity, dynamics and variability of impulses. Invariability relates to interactions with stable environment.

$E M=$ emotional variability relates to experiencing interactions with environment and situational changes. We consider dynamic of emotions and its impact in cognitive and conative area. High values represent high excitability, experiencing tension and euphoria. Low values typifies emotional stability and low emotiveness.

$R E=$ regulation variability relates to regulation functions of controlling activities. High values are characteristic for low self-control, low deliberation of possible consequences of interaction activities, anticipation of regulation of performance and behaviour.

$A D=$ adjustable variability relates to introducing into new conditions and circumstances of life and activity. High values of variability is characteristic for responding to dynamics of impact of situational variabilities with adaptive activities.

SPARO uses 34 more components, final analysis is very extensive. For needs of our research we picked only crucial components, which showed us statistically significant variations and that helped us to present key changes of mental states of freestyle cycling athletes. In our research we used group of elite track cyclists as a reference group and compared results of freestyle cyclists with these data.

\section{RESULTS}

There were several references about critical moments that matched within our test group. Insecurity during first practice lap, fatigue and lose of concentration during qualifiers and final runs, possible risk of injury during executing of tricks. Nervousness and fear of not achieving goals was frequent answer in athletes' responses.

SUPSO test: We can see the results of T-test in which we compared freestyle riders' pre-competition values with pre-competition values of the reference group (table 1). There were statistically significant variations found in two components $-U$ (anxious expectations and fears) and $S$ (sadness). 
Table 1. SUPSO test - results of comparison of precompetition mental state values of the two groups.

\begin{tabular}{|l|l|l|l|}
\hline Scale & $\mathbf{M}$ & SD & $\mathbf{t}(\mathbf{s} \mathbf{p})$ \\
\hline $\mathbf{P}$ & 28,65 & 7,89 & $-0,34$ \\
\hline $\mathbf{A}$ & 24,78 & 6,56 & 0,13 \\
\hline $\mathbf{O}$ & 7,18 & 5,94 & $-1,56$ \\
\hline $\mathbf{N}$ & 10,58 & 4,66 & $-0,28$ \\
\hline $\mathbf{D}$ & 13,43 & 5,78 & 2,20 \\
\hline $\mathbf{U}$ & 13,82 & 4,44 & $\mathbf{3 , 0 1}$ ** \\
\hline $\mathbf{S}$ & 1,56 & 3,35 & $\mathbf{- 4 , 0 1}$ ** \\
\hline
\end{tabular}

SPARO test: Another statistically significant differences were found while comparing SPARO test results of freestyle riders and the reference group (table 2). Since relatively a big number of significant differences was found, we picked only 6 components, that smartly express specificity of freestyle riders' mentality. These are EM (emotional variability), RE (regulation variability) and $A D$ (adjusting variability), IP (autostimulation), $S E$ (social exhibitionism) and $D I$ (dynamics of interaction with environment).

SPARO test also showed, that probands belong to group B3 as for taxometric coefficients.

Table 2. SPARO test - results of comparison of the two group's subjective psychological experiences.

\begin{tabular}{|c|c|c|c|c|c|c|c|c|c|c|c|c|c|}
\hline Škála & M & SD & $\mathrm{t}(\mathrm{spc})$ & Skála & M & SD & $t(s p c)$ & & \multicolumn{5}{|c|}{ TAXOMETRICKE KOEFICIENTY } \\
\hline \multicolumn{4}{|c|}{1 ROMPONENTY } & \multicolumn{4}{|c|}{ 3. NORMALTA } & & \multicolumn{2}{|c|}{$\mathrm{A} 1-\mathrm{B} 4$} & $\mathrm{~A} 2-\mathrm{B} 3$ & \multirow{2}{*}{$\begin{array}{r}\mathrm{A} 3-\mathrm{B} 2 \\
-0,03\end{array}$} & \multirow{2}{*}{$\begin{array}{r}\mathrm{A} 4-\mathrm{B} 1 \\
-0.23\end{array}$} \\
\hline KO & 1290 & 4,25 & 1,64 & VZ & 9.00 & 2,16 & $4,10^{* *}$ & & & $-0,37$ & $-0,56$ & & \\
\hline EM & 9,50 & 2,72 & $4,07 \times$ & LS & 10,10 & 3,31 & $-3.24 *$ & & \multicolumn{2}{|c|}{ C1-D4 } & C2-D3 & C3-D2 & C4-D1 \\
\hline $\mathbf{R E}$ & 10.60 & 3,06 & $3.51 \times=$ & AN & 3,49 & 328 & $3,08 *$ & & \multicolumn{2}{|c|}{0,11} & $-0,30$ & 0.23 & 0.03 \\
\hline AD & 12,10 & 2,38 & $-3,32 *$ & EX & 6,80 & 2,62 & $3,51 \cdot *$ & & & & & & \\
\hline \multicolumn{4}{|c|}{ 2. PAKTORY } & \multicolumn{4}{|c|}{ AVEROHODNOST } & & & & & & \\
\hline PV & 9,50 & 2,22 & $6,40 *=$ & $\mathbf{L}$ & 5.80 & 3,74 & $2.62{ }^{*}$ & & & & & & \\
\hline MH & 8,30 & 2,06 & 2.15 & & & & & & & & & \multirow{3}{*}{\multicolumn{2}{|c|}{$\begin{array}{l}\text { Iisk tabulky } \\
\text { aktuální } \\
\text { skupiny }\end{array}$}} \\
\hline Škála & M & SD & (spc) & Śkála & M & SD & $\mathrm{t}(\mathrm{spc})$ & Škála & M & SD & $\mathrm{t}(\mathrm{spc})$ & & \\
\hline \multicolumn{4}{|c|}{ 1. STTMULACE } & \multicolumn{4}{|c|}{ 3. INTEGROVANOST } & \multicolumn{4}{|c|}{ 5. KORERTIVNOST } & & \\
\hline SI & 10,50 & 4,14 & 1,22 & Uz & 10.80 & 3.61 & $3.85+*$ & RF & 10,50 & 2,12 & $-3,883 \times=$ & & \\
\hline IP & 12,20 & 3,43 & $3,977^{*-*}$ & EC & 820 & 3,94 & 2,17 & LO & 9,60 & 2,95 & $-3,\left.75\right|^{* 2}$ & & \\
\hline PN & 12,30 & 3,37 & 1,78 & UR & 11,90 & 3,07 & $-1,96$ & NU & 7,60 & 320 & $-2,76^{*}$ & & \\
\hline $\mathrm{DI}$ & 11,90 & 1,10 & $10,06^{\star *}$ & RR & 12,40 & 255 & $-2.61 *$ & $\mathrm{FC}$ & 7,10 & 2,73 & $-2.90{ }^{*}$ & & \\
\hline SD & 11,20 & 2,44 & $4,66^{* *}$ & OI & 12,30 & 3.59 & -2.20 & KI & 6,60 & 151 & $3,\left.36\right|^{* 0}$ & & \\
\hline OS & 12,80 & 3,65 & $5,38 \times=$ & & & & & & & & & & \\
\hline \multicolumn{4}{|c|}{ 2. RIZIKKO } & \multicolumn{4}{|c|}{4 VETAHY } & \multicolumn{4}{|c|}{ 6. SEBEPROSAZOVABNI } & & \\
\hline AS & 12,30 & 2,91 & $2,611^{*}$ & KT & 11,60 & 3,06 & $6.09+x$ & US & 12,10 & 3,48 & $|-2,64|^{\star}$ & & \\
\hline $\mathrm{AC}$ & 9,30 & 2,75 & $-1,72$ & $\mathrm{BE}$ & 8.50 & 1,78 & $-1,78$ & TO & 8,70 & 2,41 & $-2,23$ & & \\
\hline $\mathrm{TN}$ & 10,60 & 4,43 & $2,86^{*}$ & $\mathrm{KN}$ & 9,60 & 259 & $-1,71$ & PR & 10,60 & 2,99 & $-3,81 *=$ & & \\
\hline SE & 14,30 & 2,91 & $4,022^{*=}$ & $\mathrm{NE}$ & 11.90 & 3.07 & 0.51 & NS & 10,60 & 2.01 & \begin{tabular}{|l|}
0,63 \\
\end{tabular} & \multirow{2}{*}{\multicolumn{2}{|c|}{ Konec }} \\
\hline OR & 8.50 & 2,46 & $4,37 *$ & & & & & $F M$ & 12,40 & 2,72 & $-1,75$ & & \\
\hline
\end{tabular}




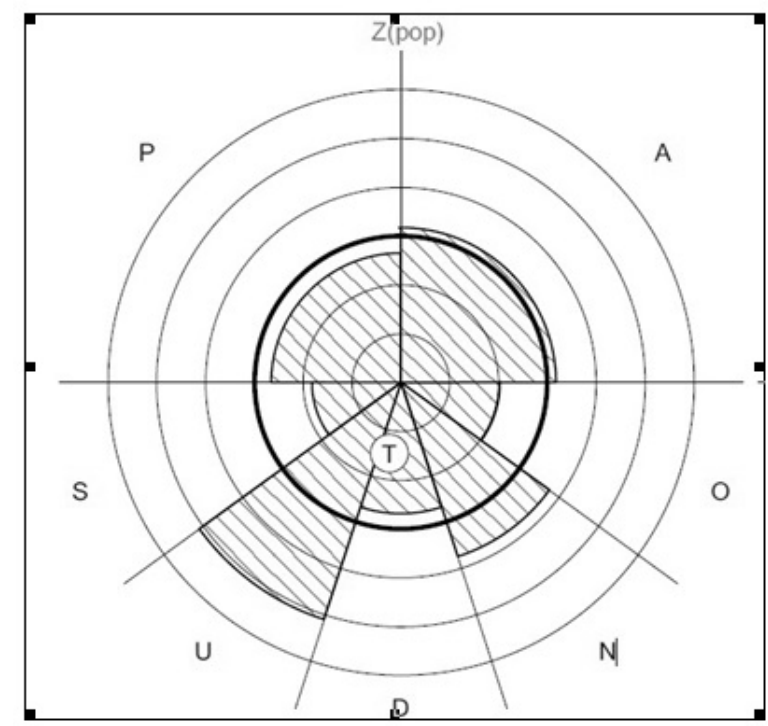

Figure 2. Target graph showing the average values of seperate components of mental state of elite freestyle cyclists.

\section{DISCUSSION AND CONCLUSIONS}

In the first part of our research we carried out a comparison of mental state of freestyle cyclists before the competition with values of the reference group (SUPSO test).

Mental state of the tested freestyle cyclists before the contest is shifted to the area of psychological discomfort in comparison with the general population, which in this case means similar percentage of components of psychological well-being $(P)$ and activity and vigorousness $(A)$, together with a lower percentage of components of depression $(D)$, impulsiveness $(O)$ and significantly lower percentage of stress $(S)$ as well as higher percentage of components of mental restlessness $(N)$ and significantly higher percentage of components of anxious expectations and fears $(U)$.

In target graph we can see graphic representation of values of evaluated psychological state of elite freestyle riders (figure 2).

In the second part of our research, we diagnosed structures and dynamics of inner and external activities' basal autoregulation and integration of freestyle cyclists (SPARO test).

We compared values of basic characteristics of tested freestyle riders's basal autoregulation and integration with values of the reference group. There were statistically significant differencies found in total of 17 components. We picked 6 components that express specificity of freestyle riders' mentality. Component of emotional variability $(E M)$ showed statistically significant variations between tested groups. Group of freestyle riders showed positive values which can be described as high excitability and inclination to take situational suspense too seriously. 
Comparison of regulation variability $(R E)$ component also showed variations of the tested groups. High values mean low self-control and low deliberation of consequences.

Another statistically significant variabilities were discovered at adjustable variability ( $A D$ - low values represent tendencies of holding on own approaches) and intensity of auto-stimulation (IP), which means that tested freestyle riders induce themselves intensive emotional enjoyments.

The highest value of statistical difference was found at dynamic interaction with environment component $(D I)$, which refers about fondness for changes, unexpectedness and high "sensitivity of experiencing of boredom".

Statistically significant difference was also found at social exhibitionism component (SE) which in our case presents tendencies of showing off and gaining admiration.

During hypothesis validation it was proved that there are statistically significant differences between values of tested groups of freestyle riders and values of the reference group, which shows us differences in mental states depending on cycling discipline. Elite freestyle riders' general and pre-competition mentality is specific, which in our opinion is caused by specificity of this extreme cycling discipline. There are numerous factors that impact these athletes during the competition, more than in any other of cycling disciplines.

Freestyle cycling athletes experience enormous pressure during the competition. Their competition runs are usually under attention of big crowd of people as this discipline is attractive and often are freestyle contests being held as highlights of multidiscipline cycling festivals. Elite riders get a lot of attention and the best of them use all the hype to enhance their performance. This extra factor brings much risk to their performance. Elite freestyle riders need to focus on their competition runs and must reduce a risk of injury, which in case of this extreme discipline is a big part of the sport, bigger than in any other cycling discipline. There are also notable crisis moments during freestyle competitions. Riders need to learn to recognize those moments, which can help them to avoid possible injuries. Study of freestyle cyclists' mental states could help them to learn how to act and focus in important moments during competition and practice, which could be beneficial to their effort in avoiding an injury and also improve their sport performance.

\section{REFERENCES}

1. Mikšík, O. (2004). Dotazník SUPSO: Př́ručka. Brno: Psychodiagnostika s.r.o.

2. Mikšík, O. (2004). Dotazník SPARO: Př́ručka. Brno: Psychodiagnostika s.r.o.

3. Blahutková, M. (1999). Rozdíly aspirační úrovně jako faktoru výkonové motivace u sportujicí a nesportujíci mládeže. 121. Brno: Masarykova univerzita, Pedagogická fakulta. 